\title{
Attitudes of physicians concerning vaccines not included in the national immunization schedule
}

\author{
Tülin Çataklı1, Aysu Duyan-Çamurdan², F. Nur Aksakal-Baran³, Ahmet Enes Güven³, \\ Ufuk Beyazova ${ }^{2}$ \\ Department of ${ }^{1}$ Pediatrics, Ankara Education and Research Hospital; Departments of ${ }^{2}$ Social Pediatrics, ${ }^{3}$ Public Health, \\ Gazi University Faculty of Medicine, Ankara, Turkey. \\ E-mail: tcatakli@gmail.com \\ Received: 6th May 2017, Revised: 22th August 2017, 26th September 2017, \\ Accepted: 18th November 2017
}

SUMMARY: Çataklı T, Duyan-Çamurdan A, Aksakal-Baran FN, Güven AE, Beyazova U. Attitudes of physicians concerning vaccines not included in the national immunization schedule. Turk J Pediatr 2018; 60: 290-297.

The aim of this study was to identify attitudes of family physicians and pediatricians working in sub-provinces of central Ankara concerning rotavirus (RV), human papilloma virus (HPV), meningococcal conjugate vaccine (MenACWY-MCV4) and adolescent and adult pertussis (Tdap) vaccines which are not included in the National Immunization Schedule (NIS). Questionnaires were conducted with 300 family physicians and 230 pediatricians who were selected by random sampling. $\mathrm{RV}$ vaccine is the most commonly recommended vaccine by physicians $(60.5 \%)$. It is the vaccine they want to be added to the NIS the most (48.5\%). Tdap vaccine is the least recommended vaccine $(24.1 \%)$ and the least preferred for inclusion in the NIS (19.6\%). Of the physicians recommending the RV vaccine $94.0 \%$ believe that " $R V$-related diarrhea cases exhibit a severe course of illness in children younger than two years old." Pediatricians recommend RV, meningoccocal and Tdap vaccines more than family physicians $(\mathrm{p}<0.05)$. Of the physicians who do not recommend RV, HPV, and conjugated meningococcal vaccine $87.5 \%, 96.7 \%$ and $27.6 \%$ found the vaccines expenive, respectively.

Of the physicians who do not recommend Tdap vaccine $90.4 \%$ think that "Tdap vaccination is not a health problem of priority for their country."

In conclusion physicians are recommending vaccines which are not included in the NIS. Their common concern for not recommending these vaccines is expensive price.

Key words: vaccine, physician, attitude, National Immunization Schedule.

The National Immunization Schedule (NIS) of Turkey includes hepatitis $\mathrm{B}(\mathrm{HepB})$, hepatitis A(HepA), tuberculosis (BCG), five-valiant combination vaccine inclusive of acellular pertussis, diphtheria, tetanus, inactive poliovirus, haemophilus influenza type b(aPDT-IPA-Hib), combination vaccine of measles-rubella- mumps (MRM), live attenuated oral polio (OPV), thirteen-valent conjugated pneumococcal vaccine (PCV13), varicella(VAR), and adolescent/adult type diphtheria- tetanus (dT) vaccines. Financial burden of all vaccines included in the NIS are carried out by the government. Rotavirus (RV), human papilloma virus (HPV), meningococcal conjugate vaccine (MenACWY-MCV4) and adolescent and adult pertussis (Tdap), which have approval for use but are not included in the NIS, are practiced upon recommendation of the physician and the will of the family. The cost of the vaccine is covered by the family or private insurance. ${ }^{1}$

Different studies conducted in Turkey have reported that a great majority of the diarrhea cases treated by hospitalization was seen in children younger than two years old. ${ }^{2}$ Of the meningococcal infections seen in $0-14$ years old children $18.4 \%$ resulted in mortality. ${ }^{3} \mathrm{HPV}$ prevelance in women is foreseen as $4.2-25 \%$ 
and expected annual cervical cancer case rate is foreseen as $1.43 / 100000 .{ }^{4}$ Immunity developed against pertussis decreases over time and thus adult and adolescent pertussis infections are the main cause for newborns and nurslings getting infected. ${ }^{5}$

In Turkey, childhood vaccination practices are mainly undertaken by family physicians and pediatricians. It is therefore important to identify the attitudes and intentions of physicians concerning practising a new vaccine before its inclusion in the NIS.

\section{Material and Methods}

The research universe consisted of 1188 family physicians working in family health centers and 505 pediatricians working in state university hospitals, private university hospitals, education and research hospitals, public hospitals and private hospitals in the sub-provinces of central Ankara/Turkey. For both groups of physicians minimum number of physicians to be reached were calculated with 50\% unknown frequency, $5 \%$ non-response speed and 95\% trust interval. Thus, it was found out that at least 230 of the 505 pediatricians and 291 of the 1188 family physicians should be interviewed. Sizes of the samples that should be reached from the two universes were calculated. The number of physicians that should be reached was determined by weighting the number of physicians working in the 3 related institution. As for pediatricians, samples were taken from five different types of hospitals (state university hospitals, private university hospitals, education and research hospitals, public hospitals and private hospitals). The number of physicians that should be reached was calculated by considering the weighted number of pediatricians in all types of hospitals and in each institution from that particular type. Physicians to be interviewed from each institution were selected by using the employee lists of the institution through simple random sampling method. All the targeted physicians were interviewed.

The research was conducted between December 2014 and May 2015. A questionnaire which was composed of 5 sections and 31 questions targeting socio-demographic characteristics of the physicians, their attitude about recommending each of the vaccines to their patients and their attitudes about the inclusion of these vaccines into the NIS was used as the data source. Required permissions were obtained from the Ethical Commission of Gazi University and the Public Health Institute of Turkey (77082166-604.01.02-16).

Collected data were analyzed by using SPSS 15.0 statistical package program. Descriptive statistics are provided as average $( \pm)$ standard deviation, median (min-max), frequency distribution and percentile. For nominal variables, Pearson's chi-squared test and Yates' corrected chi-squared tests were used as the statistical method. Histogram, P-P graphics and Kolmogorov-Smirnov tests were used for the analysis of continuous variables together with Mann-Whitney U test which was applied after normal distribution compatibility evaluation had been made. Statistical significance value was accepted $p<0.05$. For the physicians who replied "I have no idea" and "I do not have sufficient information" to the questions concerning their attitudes about recommending the four vaccines inquired and on their attitude about the inclusion of these vaccines in the NIS were excluded from the Chi-squared analysis.

The questionnaire was answered by 230 pediatricians and 300 family physicians. Questions were formulated in order to figure out socio-demographic characteristics of the physicians and their attitudes about recommending each of the vaccines to their patients and about their inclusion in the NIS. Physicians were asked not to write down their names on the questionnaire forms. They were visited by the researcher in their work places and were provided with oral information on the aim and content of the research. It took on average 10-12 minutes for a physician to complete the questionnaire. Written consent was obtained from participant physicians.

\section{Results}

In total 530 physicians participated in the research by filling in the questionnaire forms. The average ages of the participants was $43.05 \pm 8.52$, median of their ages was 44 (minmax: 26-71), average of the years spent in the profession was $18 \pm 8.40$, median of the years spent in the profession was 19 (min-max: 1-45). 
Table I. Distribution of Descriptive Characteristics of the Interviewees.

\begin{tabular}{lcc}
\hline & $\mathrm{n}$ & $\%$ \\
\hline Gender $(\mathrm{n}=520)$ & 323 & 60.9 \\
Female & 207 & 39.1 \\
Male & & \\
Work places of the interviewees $(\mathrm{n}=530)$ & 300 & 56.6 \\
Family physician & 230 & 43.3 \\
Pediatrician & & \\
Work places of the interviewees $(\mathrm{n}=530)$ & 300 & 56.6 \\
Family health center & 26 & 4.9 \\
Public hospital & 37 & 7.0 \\
Private hospital & 42 & 7.9 \\
Education and research hospital & 107 & 20.2 \\
State university hospital & 18 & 3.4 \\
Private university hospital & & 78.5 \\
Parenthood status $(\mathrm{n}=530)$ & 416 & 21.5 \\
Having child & 114 & \\
Not having child & & \\
\hline
\end{tabular}

${ }^{*}$ Column percentage

\section{Distribution of descriptive characteristics of the interviewees}

Distribution of descriptive characteristics of the interviewees are shown in Table I.

\section{Attitudes of physicians concerning recommending $R V$, HPV, meningococcal and Tdap vaccines to their patients}

Distribution of physicians' positions about recommending the RV, CMV-4 and Tdap vaccines, are shown in Table II. Among the vaccines which are not included in the NIS, RV vaccine was the most recommended one. HPV came out as the vaccine that was least practiced by the physicians for their own children.

Reasons for physicians recommending RV, HPV, meningococcal and Tdap vaccines to their patients

Physicians put forward similar reasons for recommending the vaccines which are not included in the NIS to their patients and for their will on the inclusion of these vaccines in the NIS. The percentage of physicians recommending $\mathrm{RV}$ vaccine to their patients was $60.5 \%$. Physicians recommending RV vaccine declared that " $R V$ related diarrhea had a severe course of illness in children younger than two years-old" (94\%) and that "RV vaccine decreased hospitalization" (57.7\%).
Physicians who did not recommend RV vaccine to their patients $(33.4 \%)$ thought that "the vaccine was expensive" $(87.5 \%)$, "there were no sufficient studies in our country regarding the effectiveness of this vaccine" $(27.7 \%)$ and "the vaccine had severe unwanted effects such as invagination" (2.4\%).

The precentage of the physicians who recommended meningococcal vaccine to their patients was $52.6 \%$. Physicians who recommended the vaccine thought that meningococcal diseases had high mortality and morbidity (90.6\%). Physicians who did not recommend meningococcal vaccine $(30.1 \%)$ declared the following: "the vaccine should be used only for risk groups for meningococcal infection" (87.4\%), "meningococcal infections were not a priority issue in our country" (54.0\%), "the vaccine was expensive" $(27.6 \%)$, "there were no sufficient studies in our country about the epidemiology of meningococcal disease" (20.7\%) and "available vaccines did not cover the meningococcal strains in our country sufficiently" (6.2\%).

Percentage of physicians recommending HPV vaccine to their patients was $45.6 \%$. These physicians argued that "the vaccine protected against cervical cancer" $(98.0 \%)$, "since 
Table II. Distribution of Physicians' Attitudes About the RV, MCV4, HPV and Tdap Vaccines, Which are not Included in The NIS, n (\%).*

\begin{tabular}{lcccc}
\hline & RV & MCV4 & HPV & Tdap \\
\hline Recommending the vaccine & $(\mathrm{n}=530)$ & $(\mathrm{n}=529)$ & $(\mathrm{n}=530)$ & $(\mathrm{n}=528)$ \\
Do not have sufficient information & $32(6.0)$ & $91(17.2)$ & $116(21.8)$ & $254(48.1)$ \\
Yes & $321(60.5)$ & $279(52.6)$ & $242(45.6)$ & $127(24.1)$ \\
No & $177(33.4)$ & $159(30.1)$ & $172(32.4)$ & $147(27.8)$ \\
Vaccinating own child & $(\mathrm{n}=416)$ & $(\mathrm{n}=416)$ & $(\mathrm{n}=416)$ & $(\mathrm{n}=416)$ \\
Yes & $98(23.5)$ & $85(20.4)$ & $35(8.4)$ & $54(12.9)$ \\
No & $180(43.2)$ & $233(56.0)$ & $229(55.0)$ & $298(71.6)$ \\
Not having child at eligible age & $138(33.1)$ & $98(23.5)$ & $152(36.5)$ & $64(15.3)$ \\
Recommending the vaccine to & $(\mathrm{n}=530)$ & $(\mathrm{n}=530)$ & $(\mathrm{n}=526)$ & $(\mathrm{n}=530)$ \\
relatives/acquaintances & & & & \\
Yes & $298(56.2)$ & $237(44.7)$ & $194(36.9)$ & $92(17.4)$ \\
No & $232(43.8)$ & $293(55.3)$ & $332(63.1)$ & $437(82.4)$ \\
Recommending the vaccine's inclusion & $(\mathrm{n}=530)$ & $(\mathrm{n}=528)$ & $(\mathrm{n}=529)$ & $(\mathrm{n}=528)$ \\
in the NIS & & & & \\
Do not have sufficient information & $96(18.1)$ & $159(30.1)$ & $165(31.1)$ & $297(56.2)$ \\
Yes & $257(48.5)$ & $237(44.8)$ & $194(36.7)$ & $104(19.6)$ \\
No & $177(33.4)$ & $132(25.0)$ & $170(32.1)$ & $129(24.4)$ \\
\hline
\end{tabular}

*Column percentage

NIS: National Immunization Schedule, RV: Rotavirus Vaccine, MCV4: Meningococcal Conjugate Vaccine, HPV: Human Papilloma Virus Vaccine, Tdap:Tetanus toxoid, reduced diphtheria toxoid, acellular pertussis

previously teenagers started to have sexual experience at younger ages the risk of cervical cancer increased and thus the practice of the vaccine was required" (5.0\%). Physicians who did not recommend HPV vaccine $(32.4 \%)$ declared that "the vaccine was expensive" $(96.7 \%)$, "HPV infections were not a priority issue for our country" (58.7\%) and "there were no sufficient data showing that HPV vaccine was necessary in Turkey" (45.3\%).

Physicians who recommended Tdap vaccine to their patients was $24.1 \%$. Physicians recommending Tdap vaccine argued that "in the previous years there had been an increase in adult and adolescent pertussis cases in our country" (77.1\%), "it was possible to protect newborns and little babies against pertussis by vaccinating adults and adolescents" (44.3\%) and "it was possible to adopt cocoon strategy in our country" (39.5\%). Physicians who did not recommend Tdap vaccine $(27.8 \%)$ declared that "adult and adolescent pertussis was not a priority issue for our country" (90.4\%) and "there were no sufficient data to prove that vaccination was required in our country
(36.0\%).

Factors affecting attitudes of physicians about recommending $R V, H P V$, meningococcal and Tdap vaccines to their patients

Distribution of the attitudes of physicians about recommending the vaccines which are not included in the NIS are shown in Table III, by taking into account the identifying characteristics of the physicians. This distribution revealed that pediatricians recommended $\mathrm{RV}$, meningococcal and Tdap vaccines to their patients more than family physicians did. Although recommendation of other vaccines did not vary by the gender of the physicians, it was seen that female physicians recommended Tdap vaccine to their patients more frequently. Having children, being employed in the public or private sector and the length of practicing the profession did not affect the recommendations of the physicians regarding these vaccines $(p>0.05)$. A statistically significant difference was found between the age of participant and recommendation of pertussis vaccination $(\mathrm{p}<0,05)$. The average of the ages of the participants recommending 
Table III. Distribution of Physicians' Attitudes About Recommending RV, MCV4, HPV and Tdap Vaccines, According to Their Identifying Characteristics, n (\%).*

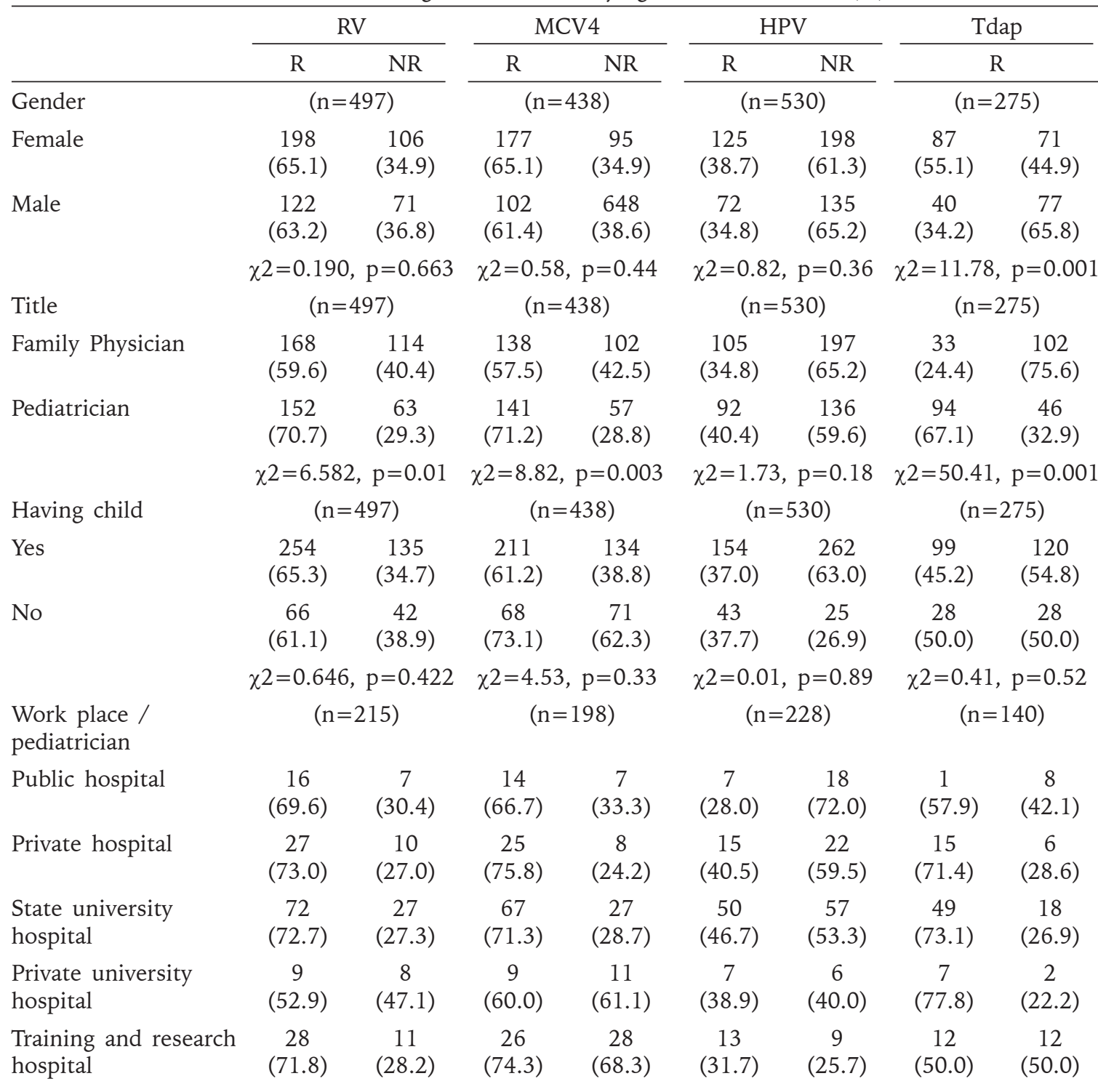

$\chi 2=2.914, \mathrm{p}=0.572 \chi 2=1.626, \mathrm{p}=0.804 \chi 2=4.682, \mathrm{p}=0.321 \chi 2=5.660, \mathrm{p}=0.226$

*Row percentage

NIS: National Immunization Schedule, R: Recommending; NR: Not recommending, RV: Rotavirus Vaccine, MCV4: Meningococcal Conjugate Vaccine, HPV: Human Papilloma Virus Vaccine, Tdap: Tetanus toxoid, reduced diphtheria toxoid, acellular pertussis

pertussis vaccination was lower. No statistically significant difference was detected between the age of the participant and recommendation of $\mathrm{RV}$, meningococcal and HPV vaccines ( $\mathrm{p}>0.05)$.

\section{Discussion}

It was detected that physicians who participated in the research recommended RV vaccine to their patients more than any of the other vaccines and opted for the inclusion of this vaccine into the NIS more than the rest of the vaccines studied. Physicians reported that cost of the vaccine prevented them from recommending the vaccine. Our findings are similar with the studies conducted on this subject. ${ }^{6-8}$ Some of the physicians declared that due to "lack of sufficient studies about the effectiveness of the vaccine in our country" they did not recommend RV vaccine. Although the data concerning $\mathrm{RV}$ vaccination coverage 
rates and the results of vaccination in our country is insufficient, results of limited number of studies which aimed at detecting the economic burden of RV infection and the cost of $\mathrm{RV}$ vaccines reveal that vaccination is cost-effective. ${ }^{9,10}$ In our opinion it is because diarrhea cases still rank high among childhood diseases in our country and that RV vaccine is the most frequently recommended vaccine among the vaccines that are not included in the NIS.

Meningococcal conjugate vaccine came out as the second highest recommended vaccine by the physicians questioned in this research and it was the second most popular vaccine that they wanted to be included in the NIS. A great majority of the physicians stated that they recommended meningococcal vaccine because rates of mortality and morbidity caused by meningococcal infections were high. Most of the physicians who did not recommend meningoccocal vaccine to their patients and who did not support its inclusion into the NIS stated that "there were not sufficient studies about meningoccocal serotypes in our country" and that "current vaccines did not cover serotypes sufficiently". In a multi-centered study covering a period between 2005-2012, in which they aimed at identifying the causes of meningitis and meningitis serotypes in Turkey, Ceyhan et al. ${ }^{3}$ reported that while the ranking changed throughout years, W135 and B had been the dominant serotypes. Studies conducted by Clark et al. ${ }^{11}$ in 2004 and by Allison et al. ${ }^{12}$ in 2011, both aiming at detecting the attitudes of physicians about recommending conjugated meningoccal vaccine, found that pediatricians recommended the vaccine more than family physicians and that the cost of the vaccine prevented physicians from recommending the vaccine. In our research a small number of physicians declared cost of the vaccine as an obstacle for their recommendation. Although meningoccocal vaccine has a price close to the $\mathrm{RV}$ vaccine, physicians have fewer concerns about the price of the meningoccocal vaccine in recommending the vaccine, which could be related with their awareness about the possible serious results that meningoccocal infections could cause.

Almost half of the physicians who participated in our study declared that they recommended
HPV vaccine to their patients. Most of the physicians who did not recommend the vaccine put forward "high prices of the vaccine" as their justification for not recommending the vaccine. This result is compatible with the findings of many other studies13-15 conducted on this subject. In some of the studies aimed at identifying physicians'attitudes about recommending the HPV vaccine, it was stated that due to the concern that "HPV vaccine might make unwanted sexual behaviours easier for adolescents" physicians were reluctant in recommending the vaccine. ${ }^{14-17}$ In our study this concern was not mentioned at all. A small number of physicians stated that "HPV vaccine should be practiced as in the recent years adolescents started to have their sexual experience at younger ages." In our country where early marriages are common ${ }^{18}$ adolescent girls and boys are at more risk for HPV infections.

In our study Tdap vaccine came out as the vaccine that was least recommended by the physicians to their patients and as the vaccine that they opted for the least for inclusion in the NIS. It was detected that pediatricians recommended Tdap vaccine more than family physicians. This result is compatible with the findings of previous studies. ${ }^{19-21}$ In our study, physicians who did not recommend the Tdap vaccine thought that "Tdap vaccination was not a primary health concern for our country". However, results of the researches ${ }^{9}$ conducted about pertussis in Turkey indicated that adult pertussis infection had high prevalence in recent years, and that adolescents and adults were sources of infection for the babies who were not vaccinated or who did not complete their vaccination process; thus, adolescent and adult vaccination was required. ${ }^{21,22}$

Studies ${ }^{23,24}$ revealed that female physicians were more inclined to recommend and practice some vaccines (like HPV) than male physicians. In our research it was detected that female physicians recommended Tdap vaccine more than male physicians and that they were more enthusiastic about its inclusion in the NIS. In Turkey Td vaccine is applied to pregnant women on a routine basis, thus female physicians might have more awareness on this issue.

In the related literature ${ }^{25}$, it is reported that physicians working in academia recommend 
new vaccines more than other physicians. In our research it was seen that, although not having statistical significance, pediatricians working in university hospitals recommended Tdap vaccine to their patients more than other group of physicians. According to the results of our research, about half of the physicians declared that "they had no information" about recommending adolescent-adult pertussis vaccine and more than half of them declared that "they had no information" about whether it should be added to NIS. It was an expected outcome that the vaccine of which there was no information was the one that was the least recommended.

Attitude of the physician about getting her/his own child vaccinated is important in that it shows her/his belief in the vaccine and that it helps the vaccine's becoming widespread. ${ }^{26,27}$ In our study, among the physicians having children who are at the age eligible for the vaccine in question, it was detected that $R V$ and meningoccocal vaccines were the most preferred ones for their children. This attitude of the physicians was compatible with their attitude about recommending the vaccines to the patients.

In the literature it is reported that physicians who are new in their profession are more inclined to recommend new vaccines. ${ }^{19,23,28}$ In our research it was found out that, the average of the ages of the physicians recommending Tdap vaccine was lower $(p<0.05)$. It can be thought that due to their up-to-date information physicians who are younger and who are new in their profession recommend vaccines that are relatively new for our country more often. As it is seen in our research, physicians' recommendations of a new vaccine which is not financed by the government are highly affected by its cost.

Questionnaires are low cost methods for collecting data on physicians' attitudes and intentions of practice about a new vaccine. Preparing a guide about the vaccines which are not included in the National Immunization Schedule based on the data collected from the physicians can contribute to the decisions to be made about the vaccines which are not yet included in our National Immunization Schedule and to the vaccination practices which have changed several times so far.
The limitation of this study might be that due to time and economic constraints it only covers physicians working in the central sub-provinces and leaves physicians working in the surrounding sub-provinces out of the scope of the research, and thus could not have reached a larger group of physicians. Planning a more comprehensive study would include the attitudes of physicians all over Turkey.

\section{REFERENCES}

1. Arısoy S, Ceyhan M, Çiftçi E, et al. The National Vaccination Schedule in Previously Healthy Children: The Practical Recommendations about Additional Vaccines. J Pediatr Inf 2014; 8: 1-6.

2. Hacimustafaoglu M, Celebi S, Agin M, Ozkaya G. Rotavirus epidemiology of children in Bursa, Turkey: A multi-centered hospital based descriptive study. Turk J Pediatr 2011; 53: 604-613.

3. Ceyhan M, Gürler N, Ozsurekci Y, et al. Meningitis caused by Neisseria Meningitidis, Hemophilus Influenzae Type B and Streptococcus Pneumoniae during 2005-2012 in Turkey. A multicenter prospective surveillance study. Hum Vaccin Immunother 2014; 10: 2706-2712.

4. Dursun P, Ayhan A, Mutlu L, et al. HPV types in Turkey: multicenter hospital based evaluation of 6388 patients in Turkish gynecologic oncology group centers. Turk Patoloji Derg 2013; 29: 210-216.

5. Cevik M, Beyazova U, Aral AL, et al. Seroprevalence of IgG antibodies against Bordetella pertussis in healthy individuals aged 4-24 years in Turkey. Clin Microbiol Infect 2008; 14: 388-390.

6. Kempe A, Patel MM, Daley MF, et al. Adoption of rotavirus vaccination by pediatricians and family medicine physicians in the United States. Pediatrics 2009; 124: e809-e816.

7. Agyeman P, Desgrandchamps D, Vaudaux B, et al. Interpretation of primary care physicians' attitude regarding rotavirus immunisation using diffusion of innovation theories. Vaccine 2009; 27: 4771-4775.

8. MacDougall DM, Halperin BA, Langley JM, MacKinnonCameron D, Li L, Halperin SA; Maritime Universal Rotavirus Vaccination Program (MURVP). Knowledge, attitudes, beliefs, and behaviors of parents and healthcare providers before and after implementation of a universal rotavirus vaccination program. Vaccine 2016; 5: 687-695.

9. Ağın M. Akut Gastroenteritli Çocuklarda Rotavirüs Sıklığı ve Kıyaslamalı Maliyet Analizi, Uzmanlık Tezi. Uludağ Üniversitesi Tıp Fakültesi Çocuk Sağlığı ve Hastalıkları Anabilim Dalı, Bursa, 2010.

10. Sancar M, Dalgıç N, Haşim O, Pullu M. Bir eğitim ve araştırma hastanesindeki rotavirüslü çocuklarda yatış maliyeti. Çocuk Enfeksiyon Dergisi 2011; 5: 7-11.

11. Clark SJ, Cowan AE, Stokley S, Bilukha O, Davis MM. Physician perspectives to inform a new recommendation for meningococcal conjugate vaccine (MCV4). J Adolesc Health 2006; 39: 850-855. 
12. Allison MA, Cohn AC, Stokley S, et al. Timing of adolescent meningococcal conjugate vaccination attitudes and practices of pediatricians and family medicine physicians. Am J Prev Med 2011; 41: 581587.

13. Ozsurekci Y, Karadag-Oncel E, Bayhan C, et al. Knowledge and attitudes about human papillomaviruses and immunization among Turkish pediatricians. Asian Pac J Cancer Prev 2013; 14: 7325-7329.

14. Vadaparampil ST, Malo TL, Kahn JA, et al. Physicians' human papillomavirus vaccine recommendations, 2009 and 2011. Am J Prev Med 2014; 46: 80-84.

15. Yıldırım M, Düzovalı Ö, Kanık A, Kırık Ö. Türkiye'deki çocuk sağlığı ve hastalıkları uzmanlarının insan papilloma virüs aşısı konusundaki bilgi ve tutumları. Çocuk Enfeksiyon Dergisi 2009; 3: 62-68. 13

16. Wong MC, Lee A, Ngai KL, Chor JC, Chan PK. Knowledge, attitude, practice and barriers on vaccination against human papillomavirus infection: a cross-sectional study among primary care physicians in Hong Kong. PLos One 2013; 8: e71827.

17. Gilkey MB, Moss JL, Coyne-Beasley T, Hall ME, Shah PD, Brewer NT. Physician communication about adolescent vaccination: How is human papillomavirus vaccine different? Prev Med 2015; 77: 181-185.

18. Yüksel-Kaptanoğlu İ, Ergöçmen B. Çocuk gelin olmaya giden yol. Sosyoloji Araştırmaları Dergisi 2012; 15: 129-161.

19. Davis MM, Broder KR, Cowan AE, et al. Physician attitudes and preferences about combined Tdap vaccines for adolescents. Am J Prev Med 2006; 31: 176-180.

20. Dempsey AF, Cowan AE, Broder KR, Kretsinger K, Stokley S, Clark SJ. Adolescent Tdap vaccine use among primary care physicians. J Adolesc Health 2009; 44: 387-393.
21. Esen B, Coplu N, Kurtoglu D, Gozalan A, Akin L. Prevalence of high anti body titers of pertussis in Turkey: reflection of circulating microorganism and a threat to infants. J Clin Lab Anal 2007; 21: 154-161.

22. Beyazova U, Yüksel N, Aksakal FN, Camurdan AD. Comparison of the reactogenicity of three different immunization schedules including diphtheria, tetanus, pertussis, Haemophilus influenza $b$ and polio vaccine in Turkey.Trans R Soc Trop Med Hyg 2013; 107: 438443.

23. Esposito S, Bosis S, Pelucchi C, et al. Pediatrician knowledge and attitudes regarding human papillomavirus disease and its prevention. Vaccine 2007; 25: 6437 6446.

24. Tissot AM, Zimet GD, Rosenthal SL, Bernstein DI, Wetzel C, Kahn JA. Effective strategies for HPV vaccine delivery the views of pediatricians. J Adolesc Health 2007; 41: 119-125.

25. Ridda I, Lindley IR, Gao Z, McIntyre P, Macintyre CR. Differences in attitudes, beliefs and knowledge of hospital health care workers and community doctors to vaccination of older people. Vaccine 2008; 26: 5633 5640.

26. Posfay-Barbe KM, Heininger U, Aebi C, Desgrandchamps D, Vaudaux B, Siegrist CA. How do physicians immunize their own children? Differences among pediatricians and nonpediatricians. Pediatrics 2005; 116: e623-e633.

27. Killian M, Detoc M, Berthelot P, et al. Vaccine hesitancy among general practitioners: evaluation and comparison of their immunisation practice for themselves, their patients and their children. Eur J Clin Microbiol Infect Dis 2016; 35: 1837-1843.

28. Jain N, Irwin KL, Montano D, et al. Family physicians' knowledge of genital human papillomavirus (HPV) infection and HPV-related conditions, United States, 2004. Fam Med 2006; 38: 483-489. 